\title{
Convergence Effect of Interpersonal Problems, Depression, Self-Esteem in Nursing College Students on Suicidal Ideation
}

\author{
Yeon-Gyung Bak ${ }^{1)}$, Hyo-Jeong Kang ${ }^{2) *}$, Sun-Yuoug Lim $^{3)}$ \\ 간호 대학생의 대인관계 문제, 우울, 자아존중감이 자살 \\ 생각에 미치는 융합적 영향 \\ 박연경1), 강효정2)*, 임선영3)
}

\begin{abstract}
This purpose of the study was to investigate the Interpersonal Problems, Depression, Self-Esteem and Suicidal Ideation of College students and relations among the factors. The data were obtained from distributing structured questionnaires to 178 nursing students in Busan and Ulsan Metropolitan City, beginning September 1th to the October 31th of 2017, and analysis by frequency, Pearson's correlation coefficient and Multiple stepwise regression. The correlation Interpersonal Problems $(r=.438, p=<.001)$ and Depression $(\mathrm{r}=.495, \mathrm{p}=<.001)$ showed to be positivity correlated. Also the correlation between Self-Esteem showed to be negativity correlated( $(\mathrm{r}=-496, \mathrm{p}=<.001)$. In addition the factors influencing the Suicidal Ideation of nursing students were Depression $(\beta=.273, p=.001)$, Interpersonal Problems $(\beta=-.231, p=.009)$, Self-Esteem $(\beta=171, p=.031)$ significant predictor and accounted for $31 \%$ of the variance in Suicidal Ideation of nursing students. The factors affecting effective intervention techniques need to be applied to the development of programs to upgrade obesity prevention of korea high school students.
\end{abstract}

Keywords: Nursing Students, Interpersonal Problems, Depression, Self-Esteem Suicidal Ideation

$$
\text { 요 약 }
$$

본 연구는 간호 대학생의 대인관계 문제, 우울 및 자아존중감이 자살 생각에 미치는 영향을 알아보기 위해 시행된 서술적 조사연구이다. 연구대상은 B 광역시와 $\mathrm{U}$ 광역시 소재의 3 개 대학의 간호학과에 재학 중인 대학생 178 명이며, 조사 기간은 2017년 4월 1일부터 5월 31일까지 진행되었다. 본 연구는

Received(June 4, 2020), Review Result(1st: July 27, 2020, 2nd: September 14, 2020), Accepted(October 28, 2020)

1) (Associate Professor) 49318 Dept. Nursing, Dongju College, 16, 55th-gil, Sari-ro, Saha-gu, Busan, Korea email: nurse2514@hanmail.net

2) (Associate Professor, Corresponding Author) 47230 Dept. Nursing, Dong-Eui Institude of Sience and

Technology, 54, Yangji-ro, Busanfin-gu, Busan, Korea

email: kanghj@dit.ac.kr

3) (Associate Professor) 44965 Dept. Nursing Science, Daehak- Gil 9, Ungchon-myeon Ulju-gun, Ulsan, Korea email: ciprovay@ch.ac.kr 
구조화된 설문지를 통해 조사 후, SPSS Statistics 22.0 프로그램을 이용하여 빈도분석, Pearson's correlation coefficient, Multiple stepwise regression으로 분석하였다. 대학생의 자살 생각은 대인관계 문 제 $(\mathrm{r}=.438, \mathrm{p}=<.001)$, 우울 $(\mathrm{r}=.495, \mathrm{p}=<.001)$, 자아존중감 $(\mathrm{r}=-496, \mathrm{p}=<.001)$ 과 유의한 상관관계를 보였으며, 간호 대학생의 자살 생각 영향 요인은 우울 $(\beta=.273, \mathrm{p}=.001)$, 대인관계 문제 $(\beta=-.231, \mathrm{p}=.009)$, 자아존중 감 $(\beta=.171, \mathrm{p}=.031)$ 으로 확인되었고, 이 요인들은 간호 대학생의 자살 생각을 총 $31 \%$ 설명하는 것으로 나타났다. 이를 통해 간호 대학생의 자살 생각에 영향 요인인 대인관계 문제와 우울을 감소하고 자아 존중감을 향상할 수 있는 자살예방 프로그램 개발이 필요하다 하겠다.

핵심어: 간호 대학생, 대인관계 문제, 우울, 자아존중감, 자살 생각

\section{1. 서론}

\section{1 연구의 필요성}

우리 사회에서 자살은 심각한 사회문제이다. 2016년도 연령별 사망 원인에 대한 통계를 살펴보면 10 대 사망 원인 1 위가 고의적 자해(자살)로 전체 사망 원인 중 $4.9 \%$ 이며, 20 대에서도 $16.4 \%, 30$ 대 $24.6 \%$ 로 10 대부터 30 대까지 자살이 사망원인 1위로 나타났다[1]. 이러한 실정에도 자살에 대한 사 회의 인식은 폐쇄적이며 자살과 관련한 연구도 한정된 주제로만 이루어지고 있다[2].

자살에 관한 선행연구는 자살로 사망한 대상을 직접 연구할 수 없어 자살을 예측할 수 있는 자 살 생각, 자살 계획, 자살 시도와 같은 요인을 중심으로 연구됐다. 이러한 예측 요인 중 자살 생각 은 죽음에 대해 일반적이고 단순하게 생각하는 것에서부터 자살을 실행하기 위한 구체적 계획을 생각하는 것까지 포함하는 포괄적 개념으로, 자살을 유도하여 자살 시도를 이끌며, 삶의 마지막 단 계까지 생각하는 것으로, 자살 생각은 자살 시도에 직접 영향을 미치며 이를 경험한 경우 추후 자 살 시도의 위험이 증가한다. 그러므로 자살 예방을 위해서는 자살 생각을 미리 확인하고 예방하는 것에서부터 시작해야 한다.

대학생 시기는 Erikson의 심리사회적발달 관점에서 보면, 친밀감 대 고립감 단계로 타인과의 의 미 있는 대인관계 형성으로 친밀감을 넓히는 시기이다. 이때 올바른 대인관계를 형성하지 못하면 고립감과 공허감 등 심리적 혼란을 느끼게 되는데, 대인관계 부적응과 정서적인 문제가 악화하고 지속되면 정신 건강상 심각한 심리적 장애가 일어날 수 있다[3]. 대인관계는 개인의 적응과 성장, 정체성의 형성에 영향을 미치는 요소로 특히 간호 대학생의 경우 임상 실습에서 환자나 보호자, 의료인 등의 다양한 대상자들을 만나기 때문에 대인관계 능력이 필수적으로 요구된다[4]. 효과적이 고 원만한 대인관계 능력은 간호 현장에서 편안한 감정을 느끼게 해주어 양질의 간호를 수행하게 하며 이 때문에 간호 대학생에게는 상당히 중요한 의미가 있다. 또한, 최근 대학생들은 불확실한 미래에 대한 불안감, 경력 쌓기 열풍에 의한 과도한 압박감, 실업과 같은 경제적 위기까지의 열악 한 조건으로 심각한 스트레스 상황에 놓인 것이 현실이다. 간호 대학생들은 타과에 비해 높은 학 업 스트레스와 교우관계, 시험, 취업 등 여러 가지 스트레스 요인에 노출되어 있으며, 국가고시와 임상 실습에서 오는 과중한 스트레스를 경험하고 있다. 이러한 대학 생활의 연속은 전공학과에 대 
한 적응의 어려움으로 이어지게 되어 중도 탈락하거나 우울 불안정한 정서를 경험하게 되고 이러 한 상황에서 벗어나는 방법의 하나로 자살을 생각한다[5].

우울은 자살을 시도했거나 지속해서 자살을 생각하는 청소년의 $40 \%$ 에서 경험하고 있으며, 우울 증상이 심할수록 자살을 시도하는 가능성이 높다고 보고하였다[6]. 특히 성인을 대상으로 한 Blatt(1974) 의 연구에서 우울증이 초기 어린 시절 경험과 밀접한 관련이 있으며, 성인기에 겪는 상실이 어린 시절 초기에 겪었던 외상을 되살려 우울 과정을 촉진 시키는 원인이 된다고 하였다[7]. 우울은 대 인관계와 관련된 의존적 우울 및 자기 정의와 관련된 자기 비난적 우울로 나뉘며, 이러한 우울 성 향은 대인관계의 행동에 다르게 나타난다[8]. 자기 비난적 우울은 적의가 있는 복종 형태로 타인과 대립하는 반면, 의존적 우울은 순응적인 행동을 하고 지배적이지 않다. 대학생으로서 삶의 전환기 에 있고 대인관계 형성을 통해 자아존중감을 발달시키는 과정에서 가치관 혼란으로 인한 스트레스 와 우울은 자살 생각의 주요 원인이 된다.

자아존중감은 자살 생각에 대한 태도나 행동에 영향을 줄 수 있는 강력한 중요 요인이므로 자 살 생각을 줄이기 위해서는 자아존중감 향상이 필요하다[5]. 자아존중감이란 자신이 자신의 행동과 이상과의 일치도에서 자기 가치를 스스로 판단하는 것으로 자아존중감의 형성은 신체적, 심리적 및 환경적 등의 다양한 변화과정에 적응해 나가야 하는 대학생 시기에 중요하다. 자아존중감이 높 은 경우 긍정적인 자아정체성이 형성되어 부정적인 경험을 할 때 자살과 같은 극단적인 선택을 하 는 경우가 적으나 자아존중감이 낮은 경우는 부정적 경험의 영향을 상대적으로 많이 받아 극단적 인 선택을 하는 경우가 있다[9]. 따라서 자아존중감은 대학생의 자살 생각의 중요한 요인이라 할 수 있다. 간호 대학생들은 향후 학과 실습 또는 임상 현장의 스트레스 상황에 잘 적응하고 자살 생각과 같은 극단적 선택을 예방하기 위해 자살 생각에 대한 내적 자원을 증진하는 것이 중요하다 사료된다.

이에 본 연구는 간호 대학생의 대인관계 문제, 우울, 자아존중감과 자살 생각 간의 관계를 확인 하고, 자살 생각에 미치는 요인을 파악하여 추후 간호 대학생을 대상으로 자살 생각 예방 교육프 로그램 개발의 기초자료를 마련하기 위하여 시도하였다.

\section{2 연구 목적}

본 연구는 간호 대학생의 대인관계 문제, 우울, 자아존중감 및 자살 생각 간의 상관관계 및 자살 생각에 영향을 미치는 요인을 규명하여 자살 예방을 위한 전략의 기초자료를 제공하고자 함이며 구체적 목적은 다음과 같다.

1) 대상자의 대인관계 문제, 우울, 자아존중감, 자살 생각 정도를 파악한다.

2) 대상자의 대인관계 문제, 우울, 자아존중감 및 자살 생각의 관련성을 파악한다.

3) 대상자의 일반적 특성과 대인관계 문제, 우울, 자아존중감이 자살 생각 영향 요인을 파악한 다. 


\section{2. 연구방법}

\section{1 연구설계}

본 연구는 간호 대학생의 대인관계 문제, 우울, 자아존중감 및 자살 생각 간의 상관관계를 파악하 고, 간호 대학생의 자살 생각 영향 요인을 알아보기 위한 서술적 조사연구이다.

\section{2 연구 대상 및 자료수집 방법}

본 연구는 C 대학교 기관생명윤리위원회의 승인(CH 201704-14)을 받은 후 시행하였다. 대상자는 B 시, $\mathrm{U}$ 시에 소재하고 있는 3 개 대학의 간호학과에 재학 중인 학생으로 연구의 목적과 익명성 보장 을 설명하고 연구에 자발적으로 참여를 허락한 자에게 자기 보고식 설문지를 배부하였다. 설문지 응답에 소요된 시간은 약 20 25분 정도였다. 자료수집 기간은 2017년 4월 1일에서 5월 31일까지 이루어졌고, 표본 수의 적절성을 확인하기 위해 G-power 3.1.7 프로그램을 이용하여 다중 회귀분 석 시 유의수준.05, 효과의 크기.2, 검정력.80, 예측변수 5 로 설정했을 때 최소 표본 크기는 150 명이 나 탈락률을 고려하여 200부를 배부하여 189 부(회수율 $95 \%$ )를 수거하였으며, 그 중 불성실한 응답 11 부를 제외한 178 부를 최종 분석하였다.

\section{3 연구의 도구}

\subsection{1 대인관계 문제}

타인과의 의미 있는 대인관계 문제를 측정하기 위하여 Hong, Park, Kim, Kwon, Choi \& Jin[10] 의 한국판 대인관계 문제 검사 원형 척도 단축형(Short form of the KIIP Circumplex scales, KIIP-SC)을 사용하였다. 이 도구는 대인관계 원형 검사와 대인관계 성격장애 검사를 통합.보완하여 한국형 대인관계 문제 척도(Korea Inventory of Interpersonal Problems, KIIP)에서 추출된 총 40 문 항으로 8 개의 하위개념인 통제지배(PA), 자기 중심성 $(\mathrm{BC})$, 냉담( $\mathrm{DE})$, 사회적 억제(FG), 비 주장성 $(\mathrm{HI})$, 과 순응성 $(\mathrm{JK})$, 자기희생 $(\mathrm{LM})$ 과 과 관여 $(\mathrm{NO})$ 로 구성된다. 하위개념은 각 5 문항으로 5 점 척도 로 이루어져 있으며 점수가 높을수록 개인이 대인관계에서 느끼는 어려움의 정도가 높음을 의미한 다.

Hong 등[10]의 연구에서 도구의 신뢰도 Cronbach's a는.61 .89이었고, 본 연구의 Cronbach's a 는.94이었다. 
우울은 미국 정신보건연구원(National Institute of Mental Health: NIMH)에 의해 일반인 대상 우 울 측정을 위해 개발된 CES-D(Center for Epidemiological Studies Depression)를 Chon, Choi \& Yang[11]이 타당화한 도구를 사용하였다. 이 도구는 총 20문항으로 지난 일주일 동안 경험한 우울 증상의 빈도에 따라 4점 Likert 척도로, 최하 0점에서 최고 60점까지며 점수가 높을수록 우울의 정 도가 심한 것을 의미한다. 이 도구의 점수가 $0 \sim 15$ 점 범위는 정상, $16 \sim 24$ 점 범위는 경도의 우울 증상, 25점 이상 범위는 중등도 이상의 우울 증상으로 분석된다. Chon 등[11]의 연구에서 도구의 신뢰도는 Cronbach's a는.91이었고, 본 연구에서 Cronbach's a는.81이었다

\subsection{3 자아존중감}

자아존중감은 자신을 가치 있는 사람으로 생각하는 정도를 의미한다. 자아존중감은 $\operatorname{Rosenberg(1965)}$ 의 자아존중감 도구(Rosenberg Self- Esteem Scale, RES)를 Jon[12]이 번역한 도구를 사용하였다. 이 도구는 총 10 문항으로 4 점 Likert 척도로, 부정 문항은 역문항으로 환산하여 최하 4 점에서 최고 40점까지며, 점수가 높을수록 자존감의 정도가 높음을 의미한다. 개발 당시 도구의 신뢰도 Cronbach's a는.85이었고, 본 연구에서 Cronbach's a는.91이었다.

\subsection{4 자살 생각}

자살 생각은 자살하는 것에 대한 생각이나 사고를 말하는 것으로 본 연구에서는 Beck, Kovacs, Weissman(1979)이 개발하고, Shin, Park과 Oh[13]가 수정 보완한 도구를 사용하였다. 이 도구는 총 19 문항으로 3점 척도이며, 최저 0점에서 최고 38점으로 점수가 높을수록 자살 생각의 정도가 높은 것을 의미한다. Shin 등[13]의 연구에서 도구의 신뢰도는 Cronbach's a는.87이었고, 본 연구에서는 Cronbach's a는.75이었다.

\section{4 자료분석}

수집된 자료는 SPSS WIN 22.0 program을 이용하여 분석하였다.

1) 대상자의 일반적 특성은 실수와 백분율로 분석하였다.

2) 대상자의 대인관계 문제, 우울, 자아존중감 및 자살 생각은 평균과 표준편차 및 최대값과 최 소값으로 분석하였다.

3) 대상자의 대인관계 문제, 우울, 자아존중감 및 자살 생각의 상관관계는 Pearson's correlation coefficient로 분석하였다.

4) 대상자의 대인관계 문제, 우울, 자아존중감이 자살 생각에 미치는 영향을 파악하기 위해 
Multiple stepwise regression으로 분석하였다.

\section{3. 연구결과}

\section{1 대상자의 일반적인 특성}

연구대상자의 일반적 특성은 다음과 같다[Table 1]. 연구대상자의 $95.5 \%(170$ 명)가 여성이고, 남성이 $4.5 \%(8$ 명)이었으며, 연령은 20세 이상 30세 미만이 64.2\%(111명), 20 세 미만이 $30.3 \%(54$ 명), 30세 이 상이 7.3\%(13명)로 나타났다. 학년은 3학년이 66.3\%(118명), 4 학년이 $33.7 \%(60$ 명)이었고 부모와 함 께 사는 경우가 $79.8 \%$ (142명)이었고 집에서 주거하는 경우가 67.4(120명)이었다. 경제 수준은 보통 인 경우가 $56.2 \%(100$ 명 $)$ 로 많았다.

[표 1] 대상자의 일반적인 특징

[Table 1] General Characteristics of Subjects

$(\mathrm{N}=178)$

\begin{tabular}{|c|c|c|c|}
\hline Variables & Categories & $\mathrm{n}$ & $\%$ \\
\hline \multirow{2}{*}{ Gender } & Man & 8 & 4.5 \\
& Female & 170 & 95.5 \\
\hline \multirow{3}{*}{ Years } & $<19$ & 54 & 30.3 \\
& $20 \sim<24$ & 111 & 62.4 \\
& $\geq 25$ & 13 & 7.3 \\
\hline \multirow{2}{*}{ Grade } & Junior & 118 & 66.3 \\
& Senior & 60 & 33.7 \\
\hline \multirow{3}{*}{ Major satisfaction } & Satisfied & 79 & 44.5 \\
& Moderate & 71 & 39.9 \\
& Dissatisfied & 28 & 15.6 \\
\hline \multirow{3}{*}{ Patents alive } & Both patets & 142 & 79.8 \\
& single & 21 & 11.8 \\
& parent / or divorce & 15 & 8.4 \\
\hline \multirow{3}{*}{ Living in together } & Etc. & 120 & 67.4 \\
& Home & 32 & 18.0 \\
& Self-boarding students & 18 & 4.1 \\
\hline \multirow{2}{*}{ Economic status } & dormitory & 8 & 27.5 \\
& Etc. & 49 & 56.2 \\
& Affluent & 100 & 16.3 \\
\hline
\end{tabular}

\section{2 대상자의 대인관계 문제, 우울, 자아존중감 및 자살 생각의 정도}

연구대상자의 대인관계 문제는 $2.28 \pm 0.64$ 점, 우울은 $0.98 \pm 0.53$ 점이었고, 자아존중감 $3.51 \pm 0.64$ 점이었 으며, 자살 생각은 $0.47 \pm 0.29$ 점이었다[Table 2]. 
[표 2] 대인관계 문제, 우울, 자아존중감과 자살 생각의 정도

[Table 2] Degree of Interpersonal Problems, Depression, Self-Esteem and Suicidal Ideation

$(\mathrm{N}=178)$

\begin{tabular}{|c|c|c|c|c|}
\hline Variables & Min & Max & Mean \pm SD & Range \\
\hline Interpersonal Problems & 1.00 & 3.90 & $2.28 \pm 0.64$ & $1-5$ \\
\hline Depression & 0.05 & 2.85 & $0.98 \pm 0.53$ & $0-3$ \\
\hline Self-Esteem & 1.90 & 5.00 & $3.51 \pm 0.64$ & $1-5$ \\
\hline Suicidal Ideation & 0.11 & 1.58 & $0.47 \pm 0.29$ & $0-2$ \\
\hline
\end{tabular}

\section{3. 대상자의 대인관계 문제, 우울, 자아존중감, 자살 생각의 상관관계}

연구대상자의 자살 생각은 대인관계 문제 $(\mathrm{r}=.485, \mathrm{p}=<.001)$, 우울 $(\mathrm{r}=.495, \mathrm{p}=<.001)$ 과 양의 상관관계, 자아존중감과는 음의 상관관계 $(\mathrm{r}=-498, \mathrm{p}=<.001)$ 로 나타났다. 자아존중감은 대인관계 문제, 우울과 음의 상관관계, 우울은 대인관계 문제와 양의 상관관계로 나타났다[Table 3].

[표 3] 대상자의 대인관계 문제, 우울, 자아존중감과 자살 생각의 상관관계

[Table 3] Relationships of Interpersonal Problems, Depression, Self-Esteem and Suicidal Ideation

$(\mathrm{N}=178)$

\begin{tabular}{|c|c|c|c|c|}
\hline \multirow{2}{*}{ Variables } & Interpersonal Problems & Depression & Self-Esteem & Suicidal Ideation \\
\cline { 2 - 5 } & $\mathrm{r}(\mathrm{p})$ & $\mathrm{r}(\mathrm{p})$ & $\mathrm{r}(\mathrm{p})$ & $\mathrm{r}(\mathrm{p})$ \\
\hline Interpersonal Problems & 1.00 & & & \\
\hline Depression & $.473(<.001)^{* *}$ & 1.00 & & \\
\hline Self-Esteem & $-.597(<.001)^{* *}$ & $-.608(<.001)^{* *}$ & 1.00 & 1.00 \\
\hline Suicidal Ideation & $.438(<.001)^{* *}$ & $.495(<.001)^{* *}$ & $-.496(<.001)^{* *}$ & \\
\hline
\end{tabular}

${ }^{*} \mathrm{p}=<.05{ }^{* *} \mathrm{p}=<.001$

\section{4 대상자의 자살 생각에 영향을 미치는 요인}

자살 생각에 통계적으로 유의한 대인관계 문제, 우울, 자아존중감을 독립변수로, 자살 생각을 종속 변수로 하여 다중 회귀분석을 실시하였다. 간호 대학생의 자살 생각의 회귀모형은 유의하게 나타 났으며 $(\mathrm{F}=27.622, \mathrm{p}<.001)$, 독립 변인 간의 독립성은 그들의 상관관계 계수가.80이상인 경우가 나타 나지 않아 독립성이 확인되었고, 공차 한계(tolerance)는 0.962 로 0.1 이상이었고 분산 팽창인자 (Variance Inflation Factor, VIF)는 1.039로 기준치인 10을 넘지 않아 다중공선성의 문제가 나타나 지 않았다. 또한 Durbin-Watson값이 2.02로 2에 근접하여 자기 상관(auto-correlation)이 없는 것을 알 수 있었다. 간호 대학생의 자살 생각에 가장 큰 영향 요인은 우울 $(\beta=.273, p<.001)$ 이었고, 다음 으로 대인관계 문제( $\beta=-.231, \mathrm{p}=.009)$, 자아존중감 $(\beta=.171, \mathrm{p}=.031)$ 순으로 확인되었으며 이 변인들 은 간호 대학생의 자살 생각의 총 $31.0 \%$ 설명력을 나타냈다[Table 4$].$ 
[표 4] 자살 생각의 영향 요인

[Table 4] Influencing Factors on Suicidal Ideation

$(\mathrm{N}=178)$

\begin{tabular}{|c|c|c|c|c|c|}
\hline Variables & $\mathrm{B}$ & $\mathrm{SE}$ & $\beta$ & $\mathrm{t}$ & $\mathrm{p}$ \\
\hline (Constant) & .518 & .209 & & 2.478 & .014 \\
\hline Interpersonal Problems & -.106 & .040 & -.231 & -2.632 & .009 \\
\hline Depression & .150 & .044 & .273 & 3.398 & .001 \\
\hline Self-Esteem & .079 & .036 & .171 & 2.169 & .031 \\
\hline \multicolumn{2}{|l}{$\mathrm{R} 2=.57$, Adj. R2=.31, F=27.622, $\mathrm{p}<.001$} & Durbin-Watson= 2.013 \\
\hline
\end{tabular}

\section{4. 논의}

본 연구는 간호 대학생의 자살 생각과 대인관계 문제, 우울 및 자아존중감 간의 상관관계를 파악 하고, 간호 대학생의 자살 생각 영향 요인을 알아보고자 하였다.

간호 대학생의 대인관계 문제는 우울과는 유의한 양의 상관관계가 나타났고 이는 Kim 등[3]의 연구와 유사한 결과이다. 즉 대인관계 문제의 정도가 높을수록 우울의 정도가 높음을 알 수 있다. 대학생 시기의 중요한 발달과업인 대인관계 형성은 그들의 발달단계에서의 삶에 큰 영향을 미친 다. 이 시기의 부적절한 대인관계 문제는 우울 증상, 불안 등의 심리적 부적응을 불러일으켜 대학 생의 우울감에 영향을 미친다. 바람직한 대인관계는 개인의 학습과 환경 적응에 필요한 정보와 심 리적 지원을 제공하면서 조직의 사회화와 성과를 촉진하는 중요한 요인이 되며 성공적인 조직구성 원의 필수조건이다. 특히 간호 대학생은 임상 실습을 경험하며 의료인과 간호 대상자 등의 다양한 관계상황을 접하게 되고 졸업 후 간호사로서 여러 대상자와 건강한 대인관계를 형성해야 하므로 대인관계 능력은 필수적이라 하겠다. 따라서 간호 대학생이 졸업 후 다양한 간호상황에서 대인관 계에 자신감을 가지고 바람직한 대인관계를 형성할 수 있도록 간호 교육과정에서부터 대인관계 능 력 향상을 위한 프로그램의 체계적인 적용이 이루어져야 한다.

간호 대학생의 대인관계 문제는 자아존중감과는 유의한 음의 상관관계를 보였다. 이는 Lee[14]의 연구 결과와 유사한 결과로 대인관계 문제 정도가 높을수록 자아존중감이 낮음을 알 수 있다. 인 간은 사회적 존재로 대개의 일은 대인관계에서 이루어진다. 자아존중감은 자신을 긍정적으로 생각 하고 자신감 있게 행동하게 하여[15] 올바른 대인관계에 큰 영향을 미치는 요인이다[16]. 간호 대학 생들은 임상 실습에서나 임상 현장에서 졸업 후 간호사로서 의료종사자, 환자 등과 같은 다양한 대상자와 상호작용을 하며 치료적 관계를 형성한다[17]. 이에 대학에서는 간호 대학생의 자아존중 감을 높일 수 있고 나아가 간호사로서 자긍심을 향상할 수 있는 프로그램 마련이 필요할 것이다.

본 연구에서 우울은 자아존중감과 유의한 음의 상관관계를 나타냈으며 이는 Kim과 $\mathrm{Kim}[18]$ 의 연구 결과와 유사하다. 이는 우울 정도가 높을수록 자아존중감의 정도가 낮아진다는 의미이다. 우 울과 자아존중감의 관계를 알아보기 위해 청소년을 대상으로 종단적 조사 연구한 $\mathrm{Kim}[19]$ 의 연구 에서 학교급이 높을수록 청소년의 자아존중감은 낮아지며, 우울은 높게 나타났으며 자아존중감과 우울은 시간 경과에도 안정적인 변인이었다. 이에 중재 방안을 마련하여 가능한 빠른 시기부터 직 

접적이고 체계적으로 적용하여야 자아존중감을 높이고 우울을 경감시키는 데 효과가 있을 것이다.

간호 대학생의 자살 생각에 영향을 미치는 요인을 확인하기 위한 회귀분석 결과 우울, 대인관계 문제, 자아존중감의 순으로 영향을 미치는 것으로 확인되었으며 이들 변인의 설명력은 총 $31.0 \%$ 설명하는 것으로 나타났다. 간호 대학생의 자살 생각에 가장 큰 영향을 미치는 변인은 우울로 나 타났는데, 이는 대학 신입생을 대상으로 연구한 선행연구[6]와 유사한 결과로 우울이 증가할수록 자살을 시도할 가능성이 큼을 의미하며 우울은 자살 생각에 가장 영향을 미치는 설명요인이 된다 고 하겠다. 우울은 자살 의도를 가지고 있는 사람들에게 발견되는 가장 일반적인 심리적 문제이고 자살 충동을 유발하는 강력한 예측 요인이다. 이를 근거로 간호 대학생의 정신건강 상태를 선별할 수 있는 장치가 필요하며 선별된 대상자들의 우울을 감소시키기 위한 간호 중재 및 적용이 필요하 다 사료된다.

다음으로 자살 생각에 영향을 미치는 변인은 대인관계 문제이었다. 이는 $\mathrm{Kim}[3]$ 의 연구 결과와 유사한 결과로, 대학생의 대인관계는 그들의 발달과업이 주변 환경과의 상호작용을 통해 이루어지 므로 매우 중요하다. 대학생들은 장기간의 경기 침체로 인한 취업 스트레스, 경제적 부모 의존으로 인해 짐스럽고 부담스러운 자신의 존재 인식 등으로 심각한 스트레스 상황에 놓이게 되고. 특히 간호 대학생들은 상대적으로 높은 학업 스트레스와 국가고시, 임상 실습 등의 학과 특성으로 과중 한 스트레스가 연속적으로 이어져 대학 생활 부적응과 함께 불안정한 정서 야기로 자살을 생각하 기도 한다[5]. 이에 간호 대학생의 특성에 맞는 대인관계 영향 요인들을 연구하여 이를 기반으로 실질적으로 도움을 줄 수 있는 간호 대학생 맞춤형 대인관계 향상프로그램 개발 및 적용이 중요할 것이다.

세 번째로 자살 생각에 영향을 미치는 요인은 자아존중감이었으며, 이는 Lee, Kim과 Lee[9]의 연구 결과를 지지하는 것으로 자아존중감은 자살에 영향을 주는 중요한 요인임을 알 수 있다. 즉, 자아존중감은 자기 자신을 긍정적으로 바라보는 태도로 부정적인 스트레스 상황에 부닥치게 될 때 극단적인 선택을 예방할 수 있게 하는 요인이다. 이에 간호 대학생이 자신의 강점을 인지하고 강 화할 수 있는 상담프로그램을 체계적으로 적용하여 스스로가 가치 있는 사람이라 느낄 수 있는 긍 정적인 경험의 제공이 중요하다. 본 연구는 연구대상자를 일부 지역의 간호 대학생으로 하여 전체 간호 대학생에게 확대하여 일반화하는 데는 제한점이 있다.

\section{5. 결론 및 제언}

본 연구는 간호 대학생의 대인관계 문제, 우울, 자아존중감이 자살 생각에 미치는 영향을 규명하 여, 이를 간호 대학생들의 건강증진 중재 계획에 필요한 기초근거자료를 제공하였다는 점에서 의 의가 있다. 간호 대학생의 자살 생각과 대인관계 문제, 우울, 자아존중감 간에는 유의한 상관관계 가 있었고, 자살 생각 영향 요인으로 우울, 대인관계 문제, 자아존중감이 확인되었다. 이에 간호 대 학생의 자살 생각을 감소시키기 위해 자아존중감 향상으로 원활한 대인관계를 형성하고 우울을 감 
소시킬 수 있는 다각적인 프로그램을 마련해야 할 것이다. 또한 간호 대학생의 입학 초기부터의 체계적 적용을 통해 문제를 조기에 발견하고 중재할 수 있는 전략을 구축해야 할 것이다.

\section{References}

[1] Statistical Analysis of Cause of Death by Age, Statistics Korea, (2016)

[2] G. S. Yoon, The influence of attitude toward suicide on suicidal ideation and behavior of Korean college students, The Graduate school of Jeonju University Counseling psychology, Master's thesis, (2016)

[3] D. O. Kim H. J. Lee, A. Y. Lee, A Study on Relationship among Positive Psychological Capital, Physical Health Status, Depression, Interpersonal Relationship and Learning Flow in Nursing Students, Journal of the Korea Convergence Society, (2020), Vol.11, No.1, pp.349-357, DOI: 10.15207/JKCS.2020.11.1.349

[4] H. W. Kwak, S. W. Hwang, A comparative study on interpersonal relationship, self-efficacy, and department satisfaction of students majoring in nursing: focus on a four-year technical college and university, Journal of Digital Convergence, (2017), Vol.15, No.2, pp.239-249, DOI: 10.14400/JDC.2017.15.2.239

[5] S. H. Kim, M. K. Kim, H. O. Back, The Effects of the Self-esteem and Frustration on Suicidal Ideation of University Students, Journal of Welfare for the correction, (2017), No.46, pp.1-18, DOI: 10.35422/cwsk.2017.46.1

[6] Y. H. Park, Influences of Experience in Suicide Risk Factors, Mental Health, Depression on Suicide Ideation in College Freshmen, Asia-pacific Journal of Multimedia Services Convergent with Art, Humanities and Sociology, (2017), Vol.7, No.2, pp.621-632, DOI: 10.35873/ajmahs.2017.7.2.060

[7] S. J. Blatt, Levels of object representation in anaclitic and introjective depression, The Psychoanalytic Study of the Child, (1974), Vol.29, No.1, pp.107-157, DOI: 10.1080/00797308.1974.11822616

[8] J. H. Kim, M. H. Hyun, The effects of intolerance of uncertainty and perceived control on worry: The mediating effects of cognitive avoidance, Korea Journal of Psychology: General, (2011), Vol.30, No.4, pp.1149-1164, UCI: G704-001037.2011.30.4.013

[9] S. Y. Lee, Y. Y. Kim, J. S. Lee, The Convergent Effect of Self-esteem, Depression, and Social support on Suicidal ideation in University Students, Journal of Digital Convergence, (2017), Vol.15, No.8, pp.323-331, DOI: $10.14400 / J D C .2017 .15 .8 .323$

[10] S. H. Hong, Y. R. Cho, J. H. Kwon, E. Y. Park, Y. H. Kim, Y. K. Jin, Short form of the Korean Inventory of Interpersonal Problems Circumplex scales(KIIP-SC), Korean Journal of Clinical Psychology, (2002), Vol.21, No.4, pp.923-940, UCI: G704-000007.2002.21.4.012

[11] K. K. Chon, S. J. Choi, B. C. Yang, Integrated Adaptation of CES-D in Korea, Korean Journal of Health Psychology, (2001), Vol.6, No.1, pp.59-76.

[12] B. J. Jon, Self-esteem : a test of its measurability, Yonsei Nonchong, (1974), Vol.11, No.1, pp.107-130.

[13] M. S. Shin, K. B. Park, K. J. Oh, J. S. Kim, A Study of Suicidal Ideation among High School Students : The Structural Relation among Depression, Hopelessness and Suicidal Ideation, Korean Journal of Clinical 
Psychology, (1990), Vol.9, No.1, pp.1-19.

[14] B. H. Lee, Effects of Empathy on Self-Esteem and Interpersonal Relation: Focused on College Students, Korean Journal of Clinical Psychology, (2019), Vol.27, No.2, pp.5-24.

[15] C. Y. An., Body Image Management Behavior, Self Respect, the Influence on Interpersonal Relations For Adult Males, The Journal of the Korea Contents Association, (2019), Vol.19, No.6, pp.620-631, DOI: 10.5392/JKCA.2019.19.06.620

[16] S. Y. Park, S. M. Koo, The Effect of Body Image and Self Esteem on Interpersonal Relationship in Nursing Students, Journal of Convergence for Information Technology, (2020), Vol.10. No.1, pp.158-168, DOI: $10.22156 / C S 4 S M B .2020 .10 .01 .158$

[17] M. J. Lee, Mediating effect of interpersonal ability on the relationship between nursing student's communicative competency and clinical performance, Gunsan National University, Master's thesis, (2018)

[18] J. S. Kim, S. U. Kim, A Converged Study on the Effects of Self-efficacy on Depression Stress, Self-esteem of Nursing Students, Journal of Convergence for Information Technology, (2019), Vol.9. No.5, pp.48-54, DOI: $10.22156 / C S 4 S M B .2019 .9 .5 .048$

[19] K. H. Kim, A Relationship Between Adolescents' Self-esteem and Depression: Comparison of data from 3 KCYPS surveyed for different periods, Journal of Youth Welfare, (2019), Vol.21, No.2, pp.69-96, DOI: 10.19034/KAYW.2019.21.2.03 